\title{
The Effect of COVID-19 Infection on Sperm Quality and Male Fertility
}

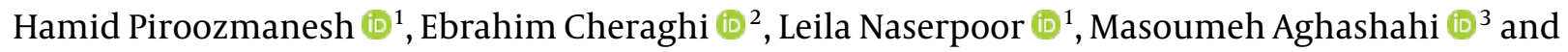 \\ Rahil Jannatifar (10), ${ }^{1}$ \\ ${ }^{1}$ Department of Reproductive Biology, Academic Center for Education Culture and Research (ACECR), Qom, Iran \\ ${ }^{2}$ Department of Biology, Faculty of Sciences, University of Qom, Iran \\ ${ }^{3}$ Department of Biology, Faculty of Sciences, Arak University, Arak, Iran \\ "Corresponding author: Department of Reproductive Biology, Academic Center for Education Culture and Research (ACECR), Qom, Iran. Email: rahiljanati2016@gmail.com \\ Received 2021 April 18; Revised 2021 May 05; Accepted 2021 May 05.
}

\begin{abstract}
Background: Coronavirus disease 2019 (COVID-19) pandemic caused by the severe acute respiratory syndrome coronavirus 2 (SARSCoV-2) may lead to the infertility of men.

Objectives: This study aimed to investigate the impact of COVID-19 infection on sperm parameters and reproductive hormones in fertile men.

Methods: A total of 100 males were selected and divided into two groups: (1) patients in convalescence (patients suffering from COVID-19 infection in pharyngeal swab in accordance with reverse-transcription polymerase chain reaction [RT-PCR] or antibodies); (2) negative control group (without antibodies). Semen and blood samples were gathered from all subjects. In the native semen, immunoglobulin(Ig) M and IgG antibodies in the blood were confirmed, and COVID-19 was detected via RT-PCR. To this end, based on the World Health Organization (WHO) guidelines, semen analysis, total antioxidant capacity (TAC), and sperm DNA integrity were assessed.

Results: Results demonstrated that sperm concentration, motility, sperm viability, and TAC significantly reduced in fertile males with virus infection. In comparison with the control group, sperm DNA integrity was significantly increased $(\mathrm{P}<0.05)$. Data indicated that the semen volume was not significantly correlated with COVID-19, and there was a significantly negative correlation between sperm concentration, sperm total motility, sperm vitality, sperm normal forms, and TAC with COVID-19. Sperm DNA fragmentation index had a significant and positive correlation with COVID-19 $(\mathrm{P}<0.05)$. In addition, reproductive hormones significantly reduced in fertile males with COVID-19 infection $(\mathrm{P}<0.05)$.
\end{abstract}

Conclusions: COVID-19 infection has a negative influence on sperm parameters and reproductive hormones in fertile males.

Keywords: COVID-19, Male Infertility, Sperm Quality, DNA Fragmentation

\section{Background}

Currently, the coronavirus disease 2019 (COVID-19) infection is threatening human health worldwide, causing acute damages in the vital organ systems (lungs, kidneys, and heart) (1). Coronavirus is divided into 46 different species and has been detected in animals and humans (2). After December 2019, COVID-19 infection increased in the world and caused concerns about the probable effect of COVID-19 on reproductive organs and fertility of males. It was reported that over 25 viruses could enter human semen and negatively affect spermatozoa or male fertility (3), such as herpes simplex virus (HSV) and human immunodeficiency viruses (HIV) (4). It is critical to know whether severe acute respiratory syndrome coronavirus 2 (SARS-CoV2) could have the same effect on males; and this was not answered in a preliminary investigation (5). COVID-19 might induce male infertility by direct viral replication and viral dissemination-induced cytopathic effects in the testis and indirect immunopathology-caused male fertility harm (6). Findings from some studies show that the coronavirus can directly affect testicular tissue and some sperm parameters by altering the expression pattern of the angiotensinconverting enzyme 2 (ACE2) gene $(7,8)$. In fact, seminiferous duct cells, spermatogonia, Leydig cells, and Sertoli cells being four testis-specific cell types, express this enzyme (8). In a study by Nikolayeva et al., it was found that the $A C E$ enzyme is located in sperm, mostly in the postacrosomal region, neck, and middle of normal sperm (7). $A C E$ expressed in sperm binds glycosyl phosphatidyl inositol (GPI) proteins to the zona pellucida region, which ultimately leads to the fertilization process (9). Furthermore, previous studies $(10,11)$ have demonstrated that ACE activity is associated with human male fertility. In addition, 
there is also the hypothesis that binding SARS-CoV-2 to the $A C E 2$ receptor increases $A C E 2$ activity in sperm cells and the side effects in fertilization owing to abnormal functions of sperm cells $(8,12,13)$. Various studies have shown that the virus and its infections reduce the rate of sex hormones (14, $15)$. Because testosterone is one of the most important hormones in male reproduction, the reduction of its level will have adverse effects on male fertility and germ cell survival (16). Thus, changes in reproductive hormone levels caused by COVID-19 infection can reduce male fertility (15).

\section{Objectives}

This study examined the impact of COVID-19 on sperm function, reproductive hormone, and total antioxidant capacity (TAC), which is closely involved in this process.

\section{Methods}

\subsection{Patient Selection}

In this case-control study, a total of 100 males referred to the Infertility Treatment Center of Qom, Iran, were enrolled from May 20 to September 24, 2020. All the 60 eligible COVID-19 patients were willing to participate in the study. All cases gave a semen sample after completing written informed consent. Subjects having a positive nasopharyngeal swab test for COVID-19 (ESwab collection kit; Copan) and positive Immunoglobulin (Ig) M and IgG antibodies were considered positive for COVID-19 (17). The control group $(n=40)$ included healthy participants without reported andrologic pathology. The age of subjects in the control group was similar to that of the COVID-19 group (mean age: 20 - 45 years). The Ethical Review Committee of Qom University approved all the study protocols (IR.Qom.REC.1399.030). The eligibility criteria of enrolling male inpatients for COVID-19 and control groups were: (1) age over 18 years; (2) having offspring through natural pregnancy or without offspring due to specific problem of one's wife; (3) lack of receiving infertility treatment such as drugs or assisted reproductive techniques; (4) lack of history of diseases affecting spermatogenesis (obesity, diabetes, cryptorchidism, varicocele, testicular torsion, mumps, genital tract infection, exposure to environmental chemicals, etc.).

\subsection{Assessment of COVID-19 RNA}

The native and processed sperm sample was centrifuged for $1 \mathrm{~min}$ at $3.500 \mathrm{rpm}$. RNA was extracted from $200 \mathrm{~mL}$ supernate by the EZ1 Virus Mini Kit v2 (Qiagen) according to the manufacturer's instructions. Then, $60 \mathrm{~mL}$ was eluted from the $200 \mathrm{~mL}$ starting material, and $5 \mathrm{~mL}$ of the eluate was examined by reverse-transcription polymerase chain reaction (RT-PCR) using the TaqMan technique. A 113-base-pair amplicon in the E-gene of COVID-19 was amplified and detected, as previously described with minor modifications (17). An ABI 7500 FAST sequence detector system (PE Applied Biosystems) was used to perform RT-PCR. Thermal cycling was performed at $55^{\circ} \mathrm{C}$ for $10 \mathrm{~min}$ for reverse transcription, followed by $95^{\circ} \mathrm{C}$ for $3 \mathrm{~min}$ and then 40 cycles of $95^{\circ} \mathrm{C}$ for $15 \mathrm{~s}, 58^{\circ} \mathrm{C}$ for $30 \mathrm{~s}$. The LightMix Modular SARS, Wuhan CoVE-gene (Cat. no. 53-0776-96), and the LightMix Modular EAV RNA Extraction Control were utilized. In addition, the AgPath-ID One-Step RT-PCR Kit (Applied Biosystems cat. no. 4387391; DNA-standard plasmid pEX-A128-nCoV2019-E-gene) was used.

\subsection{Assessment of COVID-19 Antibody}

In this study, an ELISA-based antibody method was used to measure IgG (GLKT1032 Novel Coronavirus COVID19 IgG ELISA Kit, Germany) and IgM (GLKT1033 Novel Coronavirus COVID-19 IgM ELISA Kit, Germany) levels in accordance with manufacturer's instructions. Hence, $50 \mu \mathrm{L}$ serum was assessed by the fully automatic EuroImmun Analyzer I-2 P (EuroImmun Medizinische Labordiagnostika, Germany).

\subsection{Assessment of Sperm Quality}

A semen sample of each participant was obtained by means of masturbation and ejaculated directly into noncytotoxic sterile containers. Freshly gathered semen was processed within 1 hour of ejaculation to analyze sperm parameters in accordance with the 2010 World Health Organization (WHO) semen analysis criteria (18). Eosinnigrosine staining was used to analyze the viability of sperm (eosin and nigrosine solutions 1 and 10\%, both from Merck, Germany). In this staining, the dead sperm changed to red, and the living sperm remained colorless (19).

\subsection{Assessment of DNA Fragmentation}

Sperm Chromatin Dispersion (SCD) was used to assess DNA fragmentation (20). DNA fragmentation was examined based on the presence of an aura around the nucleus and its size. Then, 200 sperms were examined to evaluate the amount of DNA fragmentation.

\subsection{Assessment of Reproductive Hormone and Total Antioxi- dant Capacity}

The levels of follicle-stimulating hormone (FSH; $\mathrm{mIU} / \mathrm{mL}$, Cat.N.DE1288), luteinizing hormone (LH; $\mathrm{mIU} / \mathrm{mL}$, Cat.N.DE1289), and total testosterone (TT; ng/mL, 
Cat.N.DE1559) were calculated by ELISA method and according to the manufacturer's instruction immunoassay (Demeditec Diagnostics GmbH, Germany). The level of TAC in seminal plasma was evaluated according to the instructions of the manufacturer's kit (CAT No. ZX-44109-192, Zell Bio GmbH, Germany).

\subsection{Statistical Analysis}

The data were analyzed and expressed as mean values \pm standard deviation. SPSS software version 21 (SPSS, Inc., USA) was utilized to proceed data. Groups were compared by unpaired sample $t$-test and Mann-Whitney test for parametric and nonparametric data, respectively. Values were statistically significant when P-value was $<0.05$.

\section{Results}

Subjects suffering from COVID-19 infection had a statistically significant impairment of sperm quality (sperm concentration, sperm motility, sperm viability, and normal sperm morphology) compared to those recovered in the control group. COVID-19 positive cases had significantly lower antioxidant capacity as well as significantly higher sperm DNA fragmentation than subjects in the control group $(\mathrm{P}<0.05)$ (Table 1 and Figure 1$)$.

Serum LH and testosterone were increased in COVID19 patients in comparison to the control group $(\mathrm{P}=0.001)$. There was no difference in serum FSH levels of the two groups $(\mathrm{P}=0.34)$. Testosterone hormone level $(\mathrm{P}=0.001)$ and the ratios of $\mathrm{T} / \mathrm{LH}(\mathrm{P}=0.001)$ and $\mathrm{FSH} / \mathrm{LH}(\mathrm{P}=0.001)$ were significantly lower in the COVID-19 group (Table 2).

Serum COVID-19 viral load had no significant correlation with semen volume $(r=0.029, P=0.8)$. Significantly negative correlations were observed between serum COVID-19 viral load and sperm concentration $(\mathrm{r}=-0.431, \mathrm{P}=$ $0.001)$, sperm motility $(\mathrm{r}=-0.603, \mathrm{P}=0.001)$, sperm viability $(\mathrm{r}=-0.750, \mathrm{P}=0.001)$, normal sperm morphology $(\mathrm{r}=$ $-0.500, \mathrm{P}=0.001)$, and seminal TAC $(\mathrm{r}=-0.355, \mathrm{P}=0.005)$. In addition, significantly positive correlations existed between serum COVID-19 viral load and sperm DNA fragmentation index $(\mathrm{r}=0.778, \mathrm{P}=0.001)$ (Table 3).

\section{Discussion}

The COVID-19 pandemic may pose a risk of infertility in males due to SARS-COV-2 (21). The higher prevalence and mortality rates from this disease in males might be due to hormonal factors, genetics, and high-risk health-related behaviors $(2,22)$. This infection directly or indirectly affects the male reproductive system, and it has a negative effect on male reproductive health and causes spermatogenic defects (15). The direct impact of the COVID-19 virus on the male reproductive system is through binding of this virus to $A C E 2$, as a receptor to enter human cells (23). It has been reported that $A C E 2$ is clearly present in the prostate, testes, epididymis, and semen of humans. This is due to the development of the testicles with age puberty, germ cell maturation, epididymal regulation, and electrolyte balance; finally, it is related to sperm capacity (24). A study found that ACE2, angiotensin $1-7$, and MAS receptors are expressed in Leydig and Sertoli cells, indicating their possible role in steroidogenesis and spermatogenesis (25).

The presence of different viruses in the male reproductive system increases the risk of sexually transmitted infections (STIs) (26). It can also affect male fertility by being infected locally or through spermatogonia stem cells (27). Although it is not clear how much these viruses are present in semen (28), it is extremely important to assess the presence of COVID-19 RNA in semen samples because even a minor risk is not reasonable in treating healthy couples for infertility reasons $(29,30)$. In this study, COVID-19 RNA did not exist in the collected semen samples. Various factors cause the virus to die in the semen. Any change in the blood-testis barrier triggers the response of inflammatory mediators and stops the immune system (31). Despite reports of transmission of COVID-19 virus through semen samples, there is no evidence of virus infection through these samples (32).

We investigated the adverse effect of COVID-19 infection on sperm parameters. The adverse impact on sperm is indicated via reduced concentrations and sperm viability, alterations in morphology, diminished motility, enhanced DNA fragmentation and significantly decreased TAC in those with good reproductive function and concomitant COVID-19 infection compared to non-infected cases. The main mechanisms of COVID-19 virus affecting sperm function and parameters can be summarized as follows: the COVID-19 virus uses the ACE2 receptor to enter human cells, which is initiated by the intramembrane serine protease TMPRSS2. Both ACE2 and TMPRSS2 receptors are expressed in the testes (33). Binding of COVID-19 virus to ACE2 can lead to an overgrowth of angiotensin II, which leads to a strong inflammatory response with dysfunction of Leydig and Sertoli cells, resulting in decreased sperm viability and function (34). Because angiotensin II is known to stimulate sperm, excess levels of this enzyme, followed by excessive $A C E 2$, can cause inflammation and affect sperm function, especially when the inflammation in the testicles is not localized (34).

On the other hand, TMPRSS2 can break down ACE2 into amino acids 697 to 716 and facilitate the entry of the COVID19 virus. The ACE2 gap is expected to reduce sperm viability and function following exposure to the virus, leading to 


\begin{tabular}{|c|c|c|c|}
\hline Parameters & COVID-19 Positive Individuals & Control Individuals & P-Value \\
\hline Age $(y)$ & $38.2 \pm 9.9$ & $36.4 \pm 13$ & 0.661 \\
\hline $\operatorname{BMI}\left(\mathrm{kg} / \mathrm{m}^{2}\right)$ & $24.6 \pm 2.9$ & $23.6 \pm 2.6$ & 0.521 \\
\hline Volume (mL) & $2.8 \pm 0.9$ & $3.1 \pm 1.0$ & 0.502 \\
\hline Sperm concentration $\left(10^{6} / \mathrm{mL}\right)$ & $70.9 \pm 63.9$ & $105.9 \pm 41.1$ & 0.001 \\
\hline Total motility (\%) & $48.1 \pm 28.0$ & $73.1 \pm 27.7$ & 0.001 \\
\hline Normal morphology (\%) & $7.33 \pm 1.88$ & $12.1 \pm 2.5$ & 0.001 \\
\hline DNA fragmentation (\%) & $16.45 \pm 2.55$ & $11.22 \pm 3.22$ & 0.01 \\
\hline Viability (\%) & $61.52 \pm 8.34$ & $87.33 \pm 9.77$ & 0.001 \\
\hline $\mathrm{TAC}(\mathrm{IU} / \mathbf{m L})$ & $2.55 \pm 1.33$ & $4.56 \pm 2.01$ & 0.001 \\
\hline
\end{tabular}

${ }^{\mathrm{a}}$ Values are expressed as mean \pm SD unless otherwise indicated.

${ }^{\mathrm{b}}$ Statistical analysis according to Mann-Whitney $\mathrm{U}$ test for nonparametric distribution $(\mathrm{P}<0.05)$.

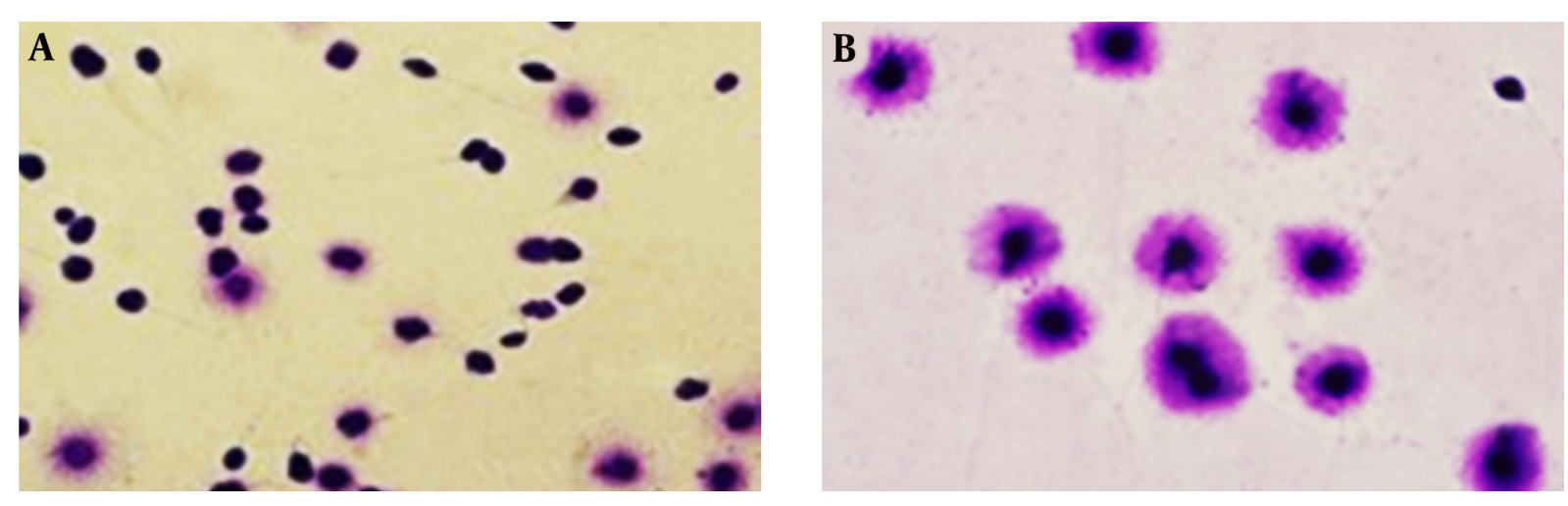

Figure 1. View of DNA fragmentation based on halo formation in different groups (magnification $\times 100$ ). A significantly higher sperm DNA fragmentation in COVID-19 positive, A, fertile males group; B, compared to the subjects in the control group. Sperm nucleus with large halo (without DNA fragmentation), sperm nucleus with small halo (with DNA fragmentation), and sperm nucleus without halo (with DNA with severe damage).

Table 2. Comparison of Hormonal Factors in COVID-19 Positive Fertile Males and Control Individuals ${ }^{\mathrm{a}, \mathrm{b}}$

\begin{tabular}{|c|c|c|c|}
\hline Hormonal Analysis & COVID-19 Positive Individuals & Control Individuals & P-Value \\
\hline FSH $(\mathbf{m I U} / \mathbf{m L})$ & $4.51 \pm 0.66$ & $5.13 \pm 0.45$ & 0.34 \\
\hline $\mathbf{L H}(\mathbf{m I U} / \mathbf{m L})$ & $6.07 \pm 0.054$ & $3.20 \pm 0.060$ & $0.001^{c}$ \\
\hline FSH/LH ratio & $0.74 \pm 0.17$ & $1.60 \pm 0.19$ & $0.001^{c}$ \\
\hline Testosterone (ng/mL) & $3.97 \pm 0.77$ & $5.79 \pm 0.53$ & $0.001^{c}$ \\
\hline Testosterone/LH ratio & $0.65 \pm 0.15$ & $1.80 \pm 0.17$ & $0.001^{c}$ \\
\hline
\end{tabular}

Abbreviations: FSH, follicle stimulating hormone; LH, luteinizing hormone.

${ }^{a}$ Values are expressed as mean \pm SD unless otherwise indicated.

${ }^{\mathrm{b}}$ Statistical analysis according to unpaired sample $t$-test and Mann-Whitney test $(\mathrm{P}<0.05)$.

${ }^{\mathrm{c}}$ Significant difference.

loss of fertility (35). Our results are similar to some recent reports describing viral infections negatively affect semen parameters, including the semen volume, number of spermatozoa, and sperm total motility. One prominent example of the adverse effects of this virus includes disarrayed spermatogenesis (27). One study examined the effect of SARSCoV-2 viral infection on semen analysis (15). The study showed that sperm quality (sperm count and motility) was significantly lower in patients with moderate viral infection. 


\begin{tabular}{|c|c|c|}
\hline \multirow{2}{*}{ Different Parameters of Sperm Quality } & \multicolumn{2}{|c|}{ COVID-19 Positive, Fertile Men } \\
\hline & $\mathbf{r}$ & P-Value \\
\hline Volume & 0.029 & 0.80 \\
\hline Sperm concentration & -0.431 & $0.001^{\mathrm{a}}$ \\
\hline Total motility & -0.603 & $0.001^{\mathrm{a}}$ \\
\hline Viability & -0.750 & $0.001^{\mathrm{a}}$ \\
\hline Sperm morphology & -0.500 & $0.001^{\mathrm{a}}$ \\
\hline TAC & -0.355 & $0.005^{\mathrm{a}}$ \\
\hline DFI & 0.778 & $0.001^{\mathrm{a}}$ \\
\hline
\end{tabular}

Abbreviations: TAC, total antioxidant capacity; DFI, DNA fragmentation index.

${ }^{\text {a }}$ Significant difference.

In another study, the hormone profile of COVID-19 patients was compared to that of healthy males with normal fertility. While there was no statistical change in serum FSH levels of the COVID-19 group, serum LH level was significantly enhanced, and testosterone $(\mathrm{T})$ and testosterone/ $\mathrm{LH}$ and $\mathrm{FSH} / \mathrm{LH}$ ratios were significantly reduced.

Androgens have very complicated relation with COVID19. Many studies show a strong impact of testosterone on the risk of COVID-19 infection (36). Gonadotropinreleasing hormone-releasing neurons secrete GnRH from the hypothalamus, which releases FSH and LH-stimulating hormone from the pituitary gland. Low levels of GnRH reduce $\mathrm{FSH}$ and $\mathrm{LH}$, resulting in dysfunction of Sertoli and Leydig cells (37). A study showed that in COVID-19 patients, serum LH levels were significantly higher, but testosterone/LH and FSH levels decreased, suggesting hypogonadism (38). Overall, testosterone/LH ratio decreases in patients with COVID-19, indicating potential subclinical damage to male gonadal function. In addition, activation of the hypothalamic-pituitary-gonadal axis and subsequent changes in hormone concentrations have an essential role in decreasing sperm quality (39).

Despite the nature of the relation between testosterone and COVID-19 disease, an andrological examination, evaluation of sperm parameters, and hormonal evaluation are necessary during the diagnosis for several months. However, COVID-19 could have a pathophysiological effect on the testes and significantly reduce the ratio of testosterone to LH by active infection of COVID-19, indicating a significant effect on the response of Leydig cells to LH stimulation (40).

\subsection{Conclusion}

COVID-19 can negatively affect spermatogenesis and male fertility. Even in subjects under treatment, it is impossible that the virus exists in semen, but the rise in body temperature associated with the disease can be impaired spermatogenesis. Thus, as a preventive measure, clinical evaluation and hormonal and semen parameters in individuals suffering from this viral disease are recommended during infection, especially in severe cases. Unfortunately, initial studies have limitations such as small sample size, testing methods, and disease progression.

\section{Acknowledgments}

We appreciate the members of the IVF Unit of Infertility Research Center of the Academic Center for Education, Culture, and Research (ACER), Qom.

\section{Footnotes}

Authors' Contribution: Study concept and design, H.P. and R.J., and M.A.; Analysis and interpretation of data, E.C., L.N., and R.J.; Drafting of the manuscript, E.C., L.N., R.J., H.P., and M.A.; Critical revision of the manuscript, E.C., L.N., and R.J.

Conflict of Interests: The authors declare that they have no competing interests.

Ethical Approval: The Ethical Review Committee of Qom University approved all the protocols used in the present study (IR.Qom.REC.1399.030).

Funding/Support: None to declare.

\section{References}

1. Zhou P, Yang XL, Wang XG, Hu B, Zhang L, Zhang W, et al. A pneumonia outbreak associated with a new coronavirus of probable bat origin. Nature. 2020;579(7798):270-3. doi: 10.1038/s41586-020-2012-7. [PubMed: 32015507]. [PubMed Central: PMC7095418]. 
2. Helmy YA, Fawzy M, Elaswad A, Sobieh A, Kenney SP, Shehata AA. The COVID-19 pandemic: A comprehensive review of taxonomy, genetics, epidemiology, diagnosis, treatment, and control. J Clin Med. 2020;9(4). doi: 10.3390/jcm9041225. [PubMed: 32344679]. [PubMed Central: PMC7230578].

3. Salam AP, Horby PW. The breadth of viruses in human semen. Emerg Infect Dis. 2017;23(11):1922-4. doi: 10.3201/eid2311.171049. [PubMed: 29048276]. [PubMed Central: PMC5652425].

4. Klimova RR, Chichev EV, Naumenko VA, Gadzhieva ZS, Tsibisov AS, Adieva AA, et al. [Herpes simplex virus and cytomegalovirus in male ejaculate: herpes simplex virus is more frequently encountered in idiopathic infertility and correlates with the reduction in sperm parameters]. Vopr Virusol. 2010;55(1):27-31. Russian. [PubMed: 20364668].

5. Paoli D, Pallotti F, Turriziani O, Mazzuti L, Antonelli G, Lenzi A, et al. SARS-CoV-2 presence in seminal fluid: Myth or reality. Andrology. 2021;9(1):23-6. doi: 10.1111/andr.12825. [PubMed: 32453494]. [PubMed Central: PMC7283802].

6. Aitken RJ. COVID-19 and human spermatozoa-Potential risks for infertility and sexual transmission? Andrology. 2021;9(1):48-52. doi: 10.1111/andr.12859. [PubMed: 32649023]. [PubMed Central: PMC7404878].

7. Nikolaeva MA, Balyasnikova IV, Alexinskaya MA, Metzger R, Franke $\mathrm{FE}$, Albrecht R2, et al. Testicular isoform of angiotensin I-converting enzyme (ACE, CD143) on the surface of human spermatozoa: revelation and quantification using monoclonal antibodies. Am J Reprod Immunol. 2006;55(1):54-68. doi: 10.1111/j.1600-0897.2005.00326.x. [PubMed: 16364013].

8. Verma S, Saksena S, Sadri-Ardekani H. ACE2 receptor expression in testes: implications in coronavirus disease 2019 pathogenesisdagger. Biol Reprod.2020;103(3):449-51. doi:10.1093/biolre/ioaa080. [PubMed: 32427288]. [PubMed Central: PMC7314215].

9. Li LJ, Zhang FB, Liu SY, Tian YH, Le F, Wang LY, et al. Human sperm devoid of germinal angiotensin-converting enzyme is responsible for total fertilization failure and lower fertilization rates by conventional in vitro fertilization. Biol Reprod. 2014;90(6):125. doi: 10.1095/biolreprod.113.114827. [PubMed: 24790158].

10. Foresta C, Mioni R, Rossato M, Varotto A, Zorzi M. Evidence for the involvement of sperm angiotensin converting enzyme in fertilization. Int J Androl. 1991;14(5):333-9. doi:10.1111/j.1365-2605.1991.tb01101.x. [PubMed: 1665481].

11. Shibahara H, Kamata M, Hu J, Nakagawa H, Obara H, Kondoh N, et al. Activity of testis angiotensin converting enzyme (ACE) in ejaculated human spermatozoa. Int JAndrol.2001;24(5):295-9. doi:10.1046/j.13652605.2001.00301.x. [PubMed: 11554987].

12. Chen YW, Lee MS, Lucht A, Chou FP, Huang W, Havighurst TC et al. TMPRSS2, a serine protease expressed in the prostate on the apical surface of luminal epithelial cells and released into semen in prostasomes, is misregulated in prostate cancer cells. Am J Pathol. 2010;176(6):2986-96. doi: 10.2353/ajpath.2010.090665. [PubMed: 20382709]. [PubMed Central: PMC2877858].

13. Li D, Jin M, Bao P, Zhao W, Zhang S. Clinical characteristics and results of semen tests among men with coronavirus disease 2019. JAMA Netw Open. 2020;3(5). e208292. doi: 10.1001/jamanetworkopen.2020.8292. [PubMed: 32379329]. [PubMed Central: PMC7206502].

14. Guan WJ, Ni ZY, Hu Y, Liang WH, Ou CQ, He JX, et al. Clinical characteristics of Coronavirus disease 2019 in China. N Engl J Med. 2020;382(18):1708-20. doi: 10.1056/NEJMoa2002032. [PubMed: 32109013]. [PubMed Central: PMC7092819].

15. Holtmann N, Edimiris $\mathrm{P}$, Andree $\mathrm{M}$, Doehmen $\mathrm{C}$, BastonBuest D, Adams O, et al. Assessment of SARS-CoV-2 in human semen-a cohort study. Fertil Steril. 2020;114(2):233-8. doi: 10.1016/j.fertnstert.2020.05.028. [PubMed: 32650948]. [PubMed Central: PMC7256599].

16. Rastrelli G, Di Stasi V, Inglese F, Beccaria M, Garuti M, Di Costanzo $D$, et al. Low testosterone levels predict clinical adverse outcomes in SARS-CoV-2 pneumonia patients. Andrology. 2021;9(1):88-98. doi: 10.1111/andr.12821. [PubMed: 32436355]. [PubMed Central: PMC7280645].

17. Corman VM, Landt O, Kaiser M, Molenkamp R, Meijer A, Chu DK, et al. Detection of 2019 novel coronavirus (2019-nCoV) by real-time RT-PCR Euro Surveill.2020;25(3). doi:10.2807/1560-7917.ES.2020.25.3.2000045. [PubMed: 31992387]. [PubMed Central: PMC6988269].

18. Cooper TG, Noonan E, von Eckardstein S, Auger J, Baker HW, Behre $\mathrm{HM}$, et al. World Health Organization reference values for human semen characteristics. Hum Reprod Update. 2010;16(3):231-45. doi 10.1093/humupd/dmp048. [PubMed: 19934213].

19. Gurr E. Staining: Animal tissues practical and theoretical. London, UK Leonard Hill; 1962. p. 170-330.

20. Evenson DP, Wixon R. Comparison of the Halosperm test kit with the sperm chromatin structure assay (SCSA) infertility test in relation to patient diagnosis and prognosis. Fertil Steril. 2005;84(4):846-9. doi: 10.1016/j.fertnstert.2005.08.009. [PubMed: 16213832].

21. Akhigbe RE, Hamed MA. Possible links between COVID-19 and male fertility. Asian Pac J Reprod. 2020;9(5):211. doi: 10.4103/2305 0500.294662.

22. La Vignera S, Cannarella R, Condorelli RA, Torre F, Aversa A, Calogero AE. Sex-specific SARS-CoV-2 mortality: Among hormone-modulated ACE2 expression, risk of venous thromboembolism and hypovitaminosis D. Int J Mol Sci. 2020;21(8). doi: 10.3390/ijms21082948. [PubMed: 32331343]. [PubMed Central: PMC7215653].

23. Fan C, Li K, Ding Y, Lu W, Wang J. ACE2 expression in kidney and testis may cause kidney and testis damage after 2019-nCoV infection. medRxiv. 2020;Preprint. doi:10.1101/2020.02.12.20022418.

24. Reis AB, Araujo FC, Pereira VM, Dos Reis AM, Santos RA, Reis FM. Angiotensin (1-7) and its receptor Mas are expressed in the human testis: Implications for male infertility. J Mol Histol. 2010;41(1):75-80. doi: 10.1007/s10735-010-9264-8. [PubMed: 20361351].

25. Valdivia A, Cortes L, Beitia M, Totorikaguena L, Agirregoitia N, Corcostegui B, et al. Role of Angiotensin-(1-7) via MAS receptor in human sperm motility and acrosome reaction. Reproduction.2020;159(3):2419. doi: 10.1530/REP-19-0274. [PubMed: 31869308].

26. Le Tortorec A, Matusali G, Mahe D, Aubry F, Mazaud-Guittot S, Houzet $\mathrm{L}$, et al. From ancient to emerging infections: The odyssey of viruses in the male genital tract. Physiol Rev. 2020;100(3):1349-414. doi: 10.1152/physrev.00021.2019. [PubMed: 32031468].

27. Li H, Xiao X, Zhang J, Zafar MI, Wu C, Long Y, et al. Impaired spermatogenesis in COVID-19 patients. EClinicalMedicine. 2020;28:100604. doi 10.1016/j.eclinm.2020.100604. [PubMed: 33134901]. [PubMed Central: PMC7584442].

28. Vahedian-Azimi A, Karimi L, Makvandi S, Jamialahmadi T, Sahebkar A A systematic review of the assessment of the presence of SARS-CoV-2 in human semen. Adv Exp Med Biol. 2021;1321:335-42. doi: 10.1007/9783-030-59261-5 30. [PubMed: 33656738].

29. Groner MF, de Carvalho RC, Camillo J, Ferreira PRA, Fraietta R. Effects of Covid-19 on male reproductive system. Int Braz J Urol. 2021;47(1):185-90. doi: 10.1590/S1677-5538.IBJU.2021.99.04. [PubMed 33047924]. [PubMed Central: PMC7712710].

30. Yao Y, Yuan X, Wu L, Guo N, Yin L, Li Y. COVID-19 and male reproduction: Current research and unknown factors. Andrology. 2021. doi: 10.1111/andr.12970. [PubMed: 33427404]. [PubMed Central: PMC8013647].

31. Wu H, Jiang X, Gao Y, Liu W, Wang F, Gong $M$, et al. Mumps virus infection disrupts blood-testis barrier through the induction of TNF-alpha in Sertoli cells. FASEB J. 2019;33(11):12528-40 doi: 10.1096/fj.201901089R. [PubMed: 31450968]. [PubMed Central: PMC6902681].

32. Kayaaslan B, Korukluoglu G, Hasanoglu I, Kalem AK, Eser F, Akinci E, et al. Investigation of SARS-CoV-2 in Semen of patients in the acute stage of COVID-19 infection. Urol Int. 2020;104(9-10):67883. doi: 10.1159/000510531. [PubMed: 32781456]. [PubMed Central: PMC7490499]. 
33. Wang $\mathrm{Z}, \mathrm{Xu} \mathrm{X}$. scRNA-seq profiling of human testes reveals the presence of the ACE2 receptor, a target for SARS-CoV-2 infection in spermatogonia, Leydig and Sertoli cells. Cells. 2020;9(4) doi: 10.3390/cells9040920. [PubMed: 32283711]. [PubMed Central: PMC7226809].

34. Illiano E, Trama F, Costantini E. Could COVID-19 have an impact on male fertility? Andrologia. 2020;52(6). e13654. doi: 10.1111/and.13654. [PubMed: 32436229]. [PubMed Central: PMC7267130].

35. Sheikhzadeh Hesari F, Hosseinzadeh SS, Asl Monadi Sardroud MA. Review of COVID-19 and male genital tract. Andrologia. 2021;53(1). e13914. doi: 10.1111/and.13914. [PubMed: 33236375]. [PubMed Central: PMC7744899].

36. Pozzilli P, Lenzi A. Commentary: Testosterone, a key hormone in the context of COVID-19 pandemic. Metabolism. 2020;108:154252. doi: 10.1016/j.metabol.2020.154252. [PubMed: 32353355]. [PubMed Central:
PMC7185012].

37. Vishvkarma R, Rajender S. Could SARS-CoV-2 affect male fertility? Andrologia. 2020;52(9). e13712. doi: 10.1111/and.13712. [PubMed: 32578263]. [PubMed Central: PMC7361071].

38. Ma L, Xie W, Li D, Shi L, Mao Y, Xiong Y, et al. Effect of SARS-CoV-2 infection upon male gonadal function: A single center-based study. MedRxiv. 2020;Preprint. doi: 10.1101/2020.03.21.20037267.

39. Li R, Yin T, Fang F, Li Q, Chen J, Wang Y, et al. Potential risks of SARS-CoV-2 infection on reproductive health. Reprod Biomed Online. 2020;41(1):89-95. doi: 10.1016/j.rbmo.2020.04.018. [PubMed: 32466994]. [PubMed Central: PMC7192111].

40. Bendayan M, Robin G, Hamdi S, Mieusset R, Boitrelle F. COVID-19 in men: With or without virus in semen, spermatogenesis may be impaired. Andrologia. 2021;53(1). e13878. doi: 10.1111/and.13878. [PubMed: 33125771]. [PubMed Central: PMC7645883]. 